\title{
Combustion Enhancers in Diesel Engines: Magnetic Field Option
}

\author{
Daniel C. Uguru-Okorie ${ }^{1}$ and Ademola A. Dare ${ }^{2}$ \\ ${ }^{I}$ The Department of Mechanical Engineering, Landmark University, Omu-Aran, Nigeria. \\ ${ }^{2}$ The Department of Mechanical Engineering, University of Ibadan, Nigeria.
}

\begin{abstract}
Particulate Matter (PM) is one of the major harmful substances in diesel exhaust gas. Technologies like the Diesel Particulate Filter (DPF) and Diesel Oxidation Catalyst (DOC) have been positioned at the exhaust to reduce the quantity of harmful substances released to the environment. This paper highlights the factors that affect combustion in diesel engines and the potential of the introduction of electromagnetic field in the combustion chamber on the improvement of the diesel engine efficiency and reduction in the quantity of Particulate Matter (PM) produced.
\end{abstract}

Keywords: Magnetic Field, Diesel Fuel, Sauter Mean Diameter, Viscosity, Combustion.

\section{Introduction}

In recent years, the issues of improving the power output of internal combustion engines per fuel, making the products of combustion exhausted from internal combustion (IC) engines environmental friendly, global warming and the rising cost of crude oil have been major sources of concern in the world.

Diesel engines have been widely used, due to their high thermal efficiency and low pollutant formation characteristics but it has a serious drawback of having a comparative larger amount of exhaust gas particulate matter (PM) which is larger than that of a gasoline engine.

The high thermal efficiency of diesel engines, mainly the direct injection diesel engine is mainly as a result of its high compression ratio, the lower pumping losses as a result of the absence of the throttle valve and the lean mixture required to achieving an efficient heterogeneous combustion process.

The production of large particulate matters (PM) has been as a result of incomplete atomization of the diesel fuel spray and mixing with the oxidizer in the combustion chamber within the short time for mixture formation and combustion. be explored.

This paper highlights various efforts at improving combustion efficiency and other potentials that can

\section{Some Efforts on Improving Combustion Efficiency}

Over the years, research has been conducted on internal combustion engines to see ways of reducing the emission of particulate matter (PM) and thereby improving the efficiency of Internal Combustion engines especially, diesel engines. The main factors that control combustion in diesel engines are the mixture formation and ignition delay.

The mixture formation deals with the mixture of fuel and oxidizer in the combustion chamber. This is controlled by the characteristics of the injection system, Sauter mean diameter of spray drop size and air swirl and turbulence in the cylinder. Efforts are thus directed at improving combustion efficiency by controlling the associated parameters associated with it. These are hereby discussed.

\section{Characteristics of Injection}

The efficiency and output of diesel engines are affected by the characteristics of the fuel spray injected into the combustion chamber. Experiments have shown better atomization of diesel spray at higher injection pressure (Carsten Baumgarten, 2006).

Diesel engine use in passenger cars was limited due to the black smoke, which was composed of soot, which is a major component of particulate matter (PM) and its large noise. The introduction of the Common-rail (CR) injection systems which is an electronically-controlled, high-pressure fuel injection system which provides better fuel atomization and multiple injections per cycle, these being advantages over the Jerk-type injection system (Kiyomi Nakakita, 2002) (http://en.wikipedia.org/wiki/Common_rail, 2012).

\section{Sauter Mean Diameter of Spray Drop Size}

The Sauter Mean Diameter is used to describe the average drop size of a spray. The smaller the average drop size of the injected spray, the greater the surface area of the fuel per volume exposed to the oxidizer and the faster and more complete the combustion process.

When diesel fuel is injected into the combustion chamber at high pressure it breaks up into smaller droplets as it penetrates the ambient gas. A faster disintegration of these spray droplets gives room for a better 
mixture formation as a result of a wider surface area of the spray droplets per volume mixing and reacting with the oxidizer. Various researchers have conducted experiments using various methods to determine the drop sizes of a diesel spray, both at high and low pressures.

Drop sizes of diesel spray were measured by a laser diffraction technique in order to study the effects of viscosity and surface tension of the fuel and also the effect of ambient pressure on a diesel spray by Hiroyasu et al (1984). He observed that increasing the injection pressure, leads to a decrease in the Sauter Mean Diameter. Hiroyasu et. al(1984), also observed that the Sauter Mean Diameter increased with an increase in the viscosity of various fluids/liquids and also an increase of the nozzle diameter, increased the sauter mean diameter of the drop size of the spray.

A decreased nozzle-orifice diameter is an effective means of reducing the Sauter Mean Diameter thereby reducing smoke. However, a decreased nozzle-orifice diameter below the optimum level, causes the momentum of the fuel spray to decrease and this reduces the spray penetration of the fuel spray. A further increase in the injection pressure is impossible in these conditions, even with a CR injection system (Kiyomi Nakakita, 2002). This leads to a decrease in the maximum output of the engine.

Empirical equations for the sauter mean diameter in terms of the operating parameters and fuel properties were proposed by Tanasawa and Toyoda, (1955), Knight (1955), Elkotb, 1982, Hiroyasu Filipovic (1969), Shipinski et al. (1983), Takeuchi et al. (1983) and Kadota, (1974).

\section{Ignition Delay}

The duration of ignition delay is one of the most important criteria, having a great effect on the combustion process, mechanical stresses, engine noise and exhaust emission. For a complete combustion in the combustion chamber of a diesel engine a shortened ignition delay period is required.

Ignition delay in diesel engines have been defined in different ways depending on the criteria used to determine the start of combustion. The two most commonly used definitions are pressure rise and illumination delays. The pressure rise delay is defined by the point at which pressure rise caused by combustion is detected on a cylinder pressure time record. The illumination delay is marked by the emission of visible radiation due to chemiluminescence or thermal radiation.

Ignition delay processes may be divided into the physical and chemical processes. In the physical delay period, the fuel is atomized, vapourized, mixed with air and raised in temperature. In the chemical delay, reaction starts slowly and then accelerates until inflammation or ignition takes place.

Experiments have shown that under temperature of $700-750^{\circ} \mathrm{K}$, temperature dependence for ignition is stronger and the chemical delay is longer than the physical delay. In a high temperature environment, temperature dependence for ignition delay is not so strong, because it is controlled by physical delay, which is the required time for mixture formation. For lighter fuel the physical delay is shorter while it is higher for heavy viscous fuels (Henein, N. and Bolt, J., 1969).

Several formulations or formulas have been proposed for ignition delays in several conditions are recorded in Henein, N. and Bolt, J. (1969), Hamamoto, et al (1975) and M. Mbarawa (2003).

\section{Use of Nano-Materials}

Deborah Elcock (2007) tried to improve combustion in diesel engines by introducing nanoscale particles of cerium oxides in diesel engine. The nano-particles where to supply oxygen to regions in the mixture that were deficient to produce a more complete combustion.

Other researchers like Walter R.M and Edward A.H. (2005) and Dongke Zhang (2009), have recorded improved performance in combustion by-products and efficiency of diesel engines with the introduction of metal and organic based nano-particles in diesel fuel.

\section{Prospects of Magnetic Field}

Researchers have found magnetic field to have an effect on the viscosity of liquids. Rongjia Toa (2004), observed a reduction in the viscosity of diesel fuel of $5.80 \mathrm{cp}$ at $10^{\circ} \mathrm{C}$ to $5.64 \mathrm{cp}$ when magnetic field of $1.1 \mathrm{~T}$ was applied to the diesel fuel for 8 Seconds. Reductions in the viscosity of fluids were also observed with the passage of magnetic field through them

Busch, K.W, (1976) stated that Chinese fishermen were said to have been applying magnets to engine fuel lines in fishing boats in order to improve fuel economy. Okoronkwo et al (2010), observed a reduction in exhaust gas emission and reduction in the diesel fuel consumption of a single cylinder, four stroke diesel engine; when magnetic field was passed through the fuel manifold. Ali A. Jazie Al-Khaledy (2008), observed an improvement in the combustion efficiency and reduction in exhaust pollutants from Perkins 1006 TAG2 generator when the generator's fuel line was lined with permanent magnets. He attributed it to the transformation of the hydrogen ion in the hydrocarbon from parahydrogen to orthohydrogen which is more unstable and reactive as a result of the influence of magnetic field on the fuel flowing in the fuel line. Ruggero 
(2000) observed that internal combustion engines emissions in general like CO, HC etc., can be reduced by fuel magnetization, stating that fuel is polarized which enhance the mixing of air and fuel thereby producing a complete combustion. Govindasamy, P. and Dhandapani, S. (2009), observed an increase in thermal efficiency and a reduction in $\mathrm{NO}_{\mathrm{x}}$ emission in a magnetic field treated fuel (composed of a blend of Bio-Diesel and Diesel) of in an Exhaust Gas Recirculation (EGR) diesel engine.

Deborah Elcock (2007), cited Envirox ${ }^{\mathrm{TM}}$ Fuel Borne Catalyst, developed by Oxonica, Ltd, which is a product that improves diesel fuel combustion, reducing fuel consumption and harmful exhaust emission. This additive is made up of nanoscale $(10 \mathrm{~nm}$ ) particles of cerium oxide. Walter R.M and Edward A.H. (2005), found that iron-magnesium catalyst when added to diesel and heavy fuel oil supplies, promotes complete and more efficient combustion in the engine, resulting in increased power, improved fuel economy and radically reduced smoke emission. Some other metals like $\mathrm{Mn}, \mathrm{Fe}, \mathrm{Cu}, \mathrm{Ba}, \mathrm{Ce}$ and $\mathrm{Pt}$ where tested, but $\mathrm{Fe}-\mathrm{Mn}$ gave better outcome. Dongke Zhang (2009) observed a 2.5\% reduction in fuel consumption and improvement in the efficiency of all types of diesel engines, when FTC/FPC diesel combustion catalysts manufactured by Fuel Technology Pty Ltd were introduced into the diesel fuel. .

\section{Conclusion}

As observed and shown in various researches conducted, that the production of exhaust particulate matter (PM) in diesel and other incomplete combustion products are as a result of incomplete atomization of spray drops within the short time for mixture formation.

Research is still needed, to find the best way to introduce a sustained magnetic field in the fuel line and combustion chamber of diesel engines. This will give an improved mixture formation by increasing the atomization process of the spray in the combustion chamber through increasing the rate of disintegration of the droplets as a result of reduction in the viscosity and surface tension of the fuel.

An increase in the rate of disintegration of the spray droplets, will also give room for a wide surface area of the spray droplets per volume to react with the oxidizer. The more surface area of droplets per volume, the more effective its evaporation and mixture formation. This will lead to a reduction in the quantity of particulate matter (PM) and increase the engine efficiency.

\section{References}

[1] Ali A. Jazie Al-Khaledy, High Performance and Low Pollutant Emissions from a Treated Diesel Fuel using a Magnetic Field, AlQadisiya Journal For Engineering Sciences; Vol. 1, pp. 2, 2008.

[2] Arai, M., Tabata, M., Hiroyasu, H. and Shimizu, M., Disintegrating Process and Spray Characterization of Fuel Jet Injected by a Diesel Nozzle, SAE Paper 85012, 1984.

[3] Busch, K.W., Busch, R.E. Darling, S.,Design of a test loop for the evaluation of magnetic water treatment devices. Process safety and environmental protection, Transactions of the Institution of Chemical Engineers, 1976.

[4] Carsten Baumgarten, Mixture Formation in Internal Combustion Engines, Springer-Verlag Berlin Heidelberg, Berlin, 2006.

[5] Deborah Elcock, Potential Impacts of Nanotechnology on Energy Transmission Applications and Needs, Environmental Science Division Argonne National Laboratory, U.S. Department of Energy laboratory, Chicago, 2007.

[6] Elkortb, M. M., Prog. Energy Comb. Sci; Vol. 8, pp. 61, 1982.

[7] Filipovic, I., Analiza motornih parametara ubrizgavanja alternativnih goriva. PhD thesis, Masinski Fakultet University, Sarajevo, 1983.

[8] Govindasamy, P. and Dhandapani, S., Effects of EGR \& Magnetic Fuel Treatment System on Engine Emission Characteristics in A Bio Fuel Engine, Proceedings of the International Conference on Mechanical Engineering 2009 (ICME2009) 26- 28 December 2009, Dhaka, Bangladesh; pp. 2-3, 2009.

[9] Hamamoto, Y., et al., Ignition Delay in Diesel Engines, Trans. of JSME; pp. 9, 1975.

[10] Henein, N. and Bolt, J., Correlation of Air Charge Temperature and Ignition Delay for Several Fuels in a Diesel Engine, SAE Paper $690252,1969$.

[11] Heywood J. B., Internal Combustion Engine Fundamentals. McGraw-Hill Book Company, 1988.

[12] Hiroyasu H, Arai M. Structures of Fuel Sprays in Diesel Engines. SAE-paper 900475, 1990.

[13] Hiroyasu, H and Kadota, T., Fuel Droplet Size Distribution in Diesel Combustion Chamber, SAE Paper 740715, 1974.

[14] Hiroyasu, H. and Arai, M., Fuel Spray Penetration and Spray Angle in Diesel Engines, Trans. Of JSME, Vol. 21; pp. 5, 1980.

[15] http://en.wikipedia.org/wiki/Common_rail, Common Rail. Retrieved $9^{\text {th }}$ of November, 2012.

[16] Kiyomi Nakakita, Research and Development Trends in Combustion Aftertreatment Systems for Next-Generation HSDI Diesel Engines. Special Issue Challenges in Realizing Clean High-Performance Engines. R \& D Review of Toyota CRDL; Vol. 37 No. 3 , 2002 .

[17] Knight, B. E., Communication on the Performance of a Type of Swirl Atomizer, Proceedings IMechE; pp. $104,1955$.

[18] Levich, V.G., Physicochemical Hydrodynamics, Prentice-Hall Inc.; 639, 1962.

[19] Mbarawa, M., A Correlation for Estimation of lgnition Delay of Dual Fuel Combustion Based on Constant Volume Combustion Vessel Experiments, R \& D Journal; vol.19 (3), 2003.

[20] Ohnesorge W., Die Bildung von Tropfen an Düsen und die Auflösung flüssiger Strahlen. Zeitschrift für angewandte Mathematik und Mechanik, Bd.16, Heft 6; pp.355-358, 1931.

[21] Okoronkwo C. A , Nwachukwu, C.C, Ngozi -Olehi L.C and Igbokwe, J.O., The effect of electromagnetic flux density on the ionization and the combustion of fuel (An economy design project), American Journal of Scientific and Industrial Research, 2010; ISSN: 2153-649X doi:10.5251/ajsir.2010.1.3.527.531

[22] Reitz R.D. Atomization and other Breakup Regimes of a Liquid Jet. Ph.D. Thesis, Princeton University, 1978.

[23] Rongjia Tao, Investigate Effects of Magnetic Fields on Fuels. Department of Physics, Temple University, Philadelpha, PA 19122; pp.7, 2004. 
[24] Ruggero Maria Santilli, Recycling liquid wastes and Crude oil into Magnegas and MagneHydrogen, Hydrogen International Conference Hy2000, Munich, German, 2000.

[25] Schweitzer, P. H., Penetration of Oil Spray, Pennsylvania State College Bulletin, 1937, p46.

[26] Shipinski, J, Myers, P. S. and Uyehara, A., A spray droplet model for diesel combustion. Proc. Instn Mech. Engrs; 184, pp. 25 - 28, 1969.

[27] Takeuchi, K., Murayama, H., Senda, J. and Yamada, K. , Droplet size distribution in diesel fuel spray. Bull. Jap. SOC. Mech. Enyrs; 26, pp. 215, 1983.

[28] Tanasawa, Y. and Toyoda, S., On the Atomization of Liquid Jet Issuing from a Cylindrical Nozzle, Technical Report of Tohoku Univ., 1955.

[29] Wakuri, Y., Fujii, M., Amitani, T. and Tsuneya, R., Studies of the Peneteration of Fuel Spray in Diesel Engine, Bulletin of JSME, pp.3-9, 1960 .

[30] Walter R.M and Edward A.H., Catalyst for Improving the Combustion Efficiency of Petroleum Fuels in Diesel Engines, Presented to the 11 Diesel Engine Emissions Reduction Conference, August 21-25, Chicago, IL, 2005.

[31] www.most.gov.mm/techuni/media/ME05023 249 280.pdf. Combustion in compression ignition engines. Retrieved $4^{\text {th }}$ July, 2012. 